\title{
Genetic Differences in Nitrate Uptake in Two Clones of the Common Reed, Phragmites australis
}

\author{
Ryoichi Araki ${ }^{1)}$, Mari Mori ${ }^{2)}$, Masashi Mori ${ }^{3)}$ and Hiroshi Hasegawa ${ }^{* 1,4)}$ \\ 1) Graduate School of Environmental Science, the University of Shiga Prefecture, 2500 Hassaka, Hikone, Shiga 522-8533, Japan \\ 2) Shiga Prefecture Agricultural Technology Promotion Center, 516 Dainaka, Azuchi, Gamou, Shiga 521-1301, Japan \\ 3) Research Institute for Bioresources and Biotechnology, Ishikawa Prefectural University, 1-308, Suematsu, Nonoichi, Ishikawa 921- \\ 8836, Japan \\ 4) School of Environmental Science, the University of Shiga Prefecture, 2500 Hassaka, Hikone, Shiga 522-8533, Japan
}

\begin{abstract}
Phragmites australis, common reed, could be useful in removing eutrophic substances from river and lake water. In this study, the genetic differences in nitrate uptake ability of the reed were investigated with a view to breeding a reed plant useful for phytoremediation. Two reed clones (W-6 and W-8) isolated from a reed community in the lakeside wetland along Lake Biwa, Japan, were used for a study on the physiological and molecular basis of nitrate uptake. $\mathrm{K}_{\mathrm{m}} \mathrm{s}$ for nitrate uptake were 80.8 and $45.2 \mu \mathrm{M}$ and $\mathrm{V}_{\max } \mathrm{s}$ for nitrate uptake were 10.62 and $2.37 \mu \mathrm{mol} \mathrm{g}^{-1}$ root f.w. $\mathrm{h}^{-1}$ in W-6 and W-8, respectively, suggesting that there were critical differences in kinetic parameters for nitrate uptake. To investigate these differences at the molecular level, we isolated a high-affinity nitrate transporter gene (NRT2) from the two reed clones and analyzed the reed NRT2 structure and expression. The deduced amino acid sequence of the reed NRT2 consisted of 523 residues and had a high similarity to NRT2 from other monocots. Reed NRT2 was strongly expressed in roots treated with $200 \mu \mathrm{M}$ nitrate. There were three amino acid substitutions of the reed NRT2 between W- 6 and W-8. Differences in NRT2 transcription were also observed between the two clones. It was not clear whether the difference in kinetic parameters for nitrate was due to the reed NRT2 structure or expression. These results indicate the possibility of selecting genotypes more useful for the removal of nitrate.
\end{abstract}

Key Words: Phragmites australis, high-affinity nitrate transporter, nitrate uptake, Michaelis-Menten kinetics, gene isolation.

\section{Introduction}

Phragmites australis, a common reed, is a well-known marsh plant that is distributed from tropical to cool-temperate zones (Koppitz 1999) and can grow under both freshwater and saline conditions (Asaeda et al. 2003), suggesting a very wide adaptability. In recent years, the reed has attracted attention as a useful plant for removing eutrophic substances to improve river and lake water quality. Furthermore, genetic diversity among reed populations has been reported worldwide (Koppits 1999), and polyploidy and isozyme polymorphisms have been demonstrated in the reed communities along Lake Biwa (Ishii and Kadono 2001, Nomiyama et al. unpublished).

At present, a serious environmental problem in lakes such as Lake Biwa (Shiga Prefecture, Japan) is the phenomenon of algal bloom, which is caused by an excess of nitrogen and phosphorus in the lake water. Eutrophic substances such as nitrate, ammonium and phosphate must be removed

Communicated by Y. Sato

Received September 6, 2004. Accepted April 18, 2005.

*Corresponding author (e-mail: hasegawa@ses.usp.ac.jp) from the lake and river water to prevent this phenomenon. Not only prevention of nitrate leakage from paddy and upland fields into the lake, but also removal of nitrate is important, because nitrate is a major source of the nitrogen excess. For this purpose, the reed is thought to be useful for taking up nitrates without using fossil and atomic energy, and projects on restoration of reed communities have been started. To evaluate how efficiently nitrate can be removed by the reed, we need to understand the nitrate uptake mechanism of the reed.

In higher plants, nitrate is taken up by nitrate transporters located in the plasma membrane of root surface cells (Tsay et al. 1993, Forde 2000, Orsel et al. 2002a). There are two nitrate transport systems, the high-affinity transport system (HATS) at a low nitrate concentration $(<1 \mathrm{mM})$ and the low-affinity transport system (LATS) at a high nitrate concentration ( $>1 \mathrm{mM}$ ) (Forde 2000). HATS is induced by nitrate (iHATS) or is constitutively expressed (cHATS) (Wang and Crawford 1996). HATS and LATS are encoded by a high-affinity nitrate transporter gene (NRT2) and a lowaffinity nitrate transporter gene (NRT1), respectively, and both genes are identified and characterized at a molecular level in several higher plant species (Tsay et al. 1993, 
Trueman et al. 1996, Quesada et al. 1997, Krapp et al. 1998). NRT2 is found in several families (Forde 2000, Orsel et al. 2002b).

The nitrate concentration of river water flowing into Lake Biwa is estimated to be less than $100 \mu \mathrm{M}$ (Lake Biwa Research Institute 2002). Therefore, NRT2 probably plays a major role in removing nitrate from the river water. In this paper, we report on the structure and function of the reed NRT2 and discuss the possibility of manipulating the reed $N R T 2$ as the first step of breeding of reed with higher nitrate removal potential.

\section{Materials and Methods}

\section{Plant materials and cultivation}

Two reed clones, named W-6 and W-8, were isolated from seeds obtained from plants growing naturally on the lakeside of Lake Biwa in Moriyama-City, Shiga Prefecture, Japan and maintained at the Shiga Prefecture Agricultural Research Center. Two reed clones randomly chosen from these clones were used in this experiment. They were cultivated hydroponically in $60 \mathrm{~L}$ plastic containers with a water culture solution containing nitrate as a sole nitrogen source in a greenhouse kept at over $15^{\circ} \mathrm{C}$. The composition of the culture medium was $\mathrm{KNO}_{3} 0.2022 \mathrm{~g} / \mathrm{L}, \mathrm{Ca}\left(\mathrm{NO}_{3}\right)_{2} \cdot 4 \mathrm{H}_{2} \mathrm{O}$ $0.2362 \mathrm{~g} / \mathrm{L}, \mathrm{KH}_{2} \mathrm{PO}_{4} 0.068 \mathrm{~g} / \mathrm{L}, \mathrm{MgSO}_{4} \cdot 7 \mathrm{H}_{2} \mathrm{O} 0.1232 \mathrm{~g} / \mathrm{L}$, $\mathrm{FeCl}_{3} \cdot 6 \mathrm{H}_{2} \mathrm{O} 0.0288 \mathrm{~g} / \mathrm{L}$, citric acid $0.0228 \mathrm{~g} / \mathrm{L}, \mathrm{MnCl}_{2}$. $4 \mathrm{H}_{2} \mathrm{O} 0.0036 \mathrm{~g} / \mathrm{L}$, and $\mathrm{H}_{3} \mathrm{BO}_{3} 0.0058 \mathrm{~g} / \mathrm{L}$. Other minor elements were present in the tap-water. Throughout the cultivation, the water level was kept about $10 \mathrm{~cm}$ above the root.

To propagate small plants from each clone, we cut culms at the water surface. After removal of leaves, culms were laid on a plastic tray filled with distilled water in a growth chamber, controlled at $27^{\circ} \mathrm{C}$ and $60 \%$ relative humidity. After two weeks, small plants that had developed to more than $2 \mathrm{~cm}$ from each node were excised from each side of the node. These plants were wrapped with urethane at the basal part of the shoot and were inserted into holes made in polystyrene foam covering the top of a $15 \mathrm{~L}$ container filled with a culture solution as described above. Plants were cultivated in the growth chamber under the same conditions as described above. One or two weeks later, small plants with two or three expanding leaves were used for measuring nitrate uptake.

\footnotetext{
Nitrate uptake measurement

Small plants were cultured using a $400 \mu \mathrm{M} \mathrm{CaSO}_{4}$ solution for nitrate starvation for 24 hours and then were transferred into the $50 \mathrm{ml}$ solution containing $200 \mu \mathrm{M} \mathrm{KNO}_{3}$ and $400 \mu \mathrm{M} \mathrm{CaSO}_{4}$ to induce nitrate uptake for 16 hours. After the induction, each small plant was soaked in a $50 \mathrm{ml}$ solution containing $10-400 \mu \mathrm{M} \mathrm{KNO}_{3}$ with $400 \mu \mathrm{M} \mathrm{CaSO}_{4}$ in a biotron (Nippon Medical and Chemical Instruments, Japan) controlled at $25^{\circ} \mathrm{C}$ under fluorescent lighting $\left(70.9 \mu \mathrm{mol} \mathrm{m}^{-2}\right.$ $\mathrm{s}^{-1}, 16 \mathrm{~h}$ photoperiod). After 2 hours, the nitrate concentration of the solution was measured by ionchromatography
}

(DX-3000, Dionex, USA) using an anion-specific column (IonPacR AS12A, Dionex, USA). The fresh weight of each plant was also measured. The nitrate uptake was evaluated by the disappearance of nitrate from the solution. Analysis of nitrate uptake with Michaelis-Menten kinetics was carried out using the same method as Hasegawa and Ichii (1994). Each experiment with five to ten plants was replicated three times.

\section{Isolation of the reed NRT2}

The mRNA of the root treated with $400 \mu \mathrm{M} \mathrm{KNO}_{3}$ and $400 \mu \mathrm{M} \mathrm{CaSO}{ }_{4}$ solution for 16 hours was purified with a QuickPrep micro mRNA purification kit (Amersham Bioscience, USA). Complimentary DNA was constructed from the RNA. The $642 \mathrm{bp}$ fragment of the reed NRT2 ORF was amplified by RT-PCR using two primers (P-RT-1: 5'-ATGA GCACCATGTTCAACAG-3', P-RT-2: 5'-CAGAAGGAGA AGAGGACCAT-3') designed based on the Oryza sativa high-affinity nitrate transporter gene sequence (OsNRT2: GenBank accession no. AB008519). The program of the PCR amplification step was $94^{\circ} \mathrm{C}$ for 5 min for 1 cycle followed by $94^{\circ} \mathrm{C}$ for $30 \mathrm{sec}, 55^{\circ} \mathrm{C}$ for $30 \mathrm{sec}$, and $68^{\circ} \mathrm{C}$ for 50 sec for 30 cycles. As a result, a putative reed NRT2 fragment was obtained.

The reed NRT2 termini were cloned by $5^{\prime}$ - and $3^{\prime}-$ RACE-PCR using a 5'-Full RACE Core set and 3'-Full RACE Core set (TaKaRa, Japan), respectively, following the manufacturer's protocol. An oligonucleotide P-3'-1: 5'CCATTACCGCCATGGTCCTCTTCTCCTTCTG-3' was used for 3'-RACE-PCR with the 3-site adaptor primer (3'Full RACE Core set: TaKaRa, Japan). Five specific primers were prepared for $5^{\prime}$-RACE as indicated in the $5^{\prime}$-RACE kit manufacturer's protocol, P-5'-5: 5'-P-CGCACTTGCGGAT GA-3', P-5'-4: 5'-GCTGTTGAACATGGTGCTCA-3', P5'-2: 5'-GTTCACCGTCCCGATGATCT-3', P-5'-3: 5'-CTC CTCATGCCGCTCGTCTA-3' and P-5'-1: 5'-CCACGCAG CTCCTCATG-3'. The full-length of the reed NRT2 was amplified using P-RT5: 5'-GCAGCAAGTCCAAGAAAGAAG CTAG-3' containing the revealed sequence in RACE and the 3-site adaptor primer (3'-Full RACE Core set, TaKaRa, Japan). The amplification was carried out as follows: $94^{\circ} \mathrm{C}$ for $2 \mathrm{~min}$, then $35 \mathrm{cycles}$ of $94^{\circ} \mathrm{C}$ for $25 \mathrm{sec}, 59^{\circ} \mathrm{C}$ for $30 \mathrm{sec}$ and $72^{\circ} \mathrm{C}$ for $2 \mathrm{~min}$.

\section{Sequence analysis}

The PCR products were integrated with $\mathrm{pCR}^{\circledR} 4$ $\mathrm{TOPO}^{\circledR}$ vector (Invitrogen, USA) for sequencing. Sequencing was performed using a BigDye ${ }^{\circledR}$ Terminator v1.1 Cycle Sequencing kit (Applied Biosystems, USA) and an ABI Prism 310 Genetic Analyzer (Applied Biosystems, USA) according to the manufacturer's instructions or ordered from Hokkaido System Science Co., LTD., Japan.

\section{Southern blot analysis}

Southern blot analysis was performed according to the Roche Molecular Biochemicals DIG Application Manual 
for Filter Hybridization (Roche Japan, Japan). A DIGlabeled RNA probe containing $642 \mathrm{nt}$ of the reed NRT2 sequence was prepared using the cDNA integrated with $\mathrm{pCR}^{\circledR} 4-\mathrm{TOPO}^{\circledR}$ vector (Invitrogen, USA) and T3 and T7 RNA polymerase (Stratagene, USA; DIG RNA Labeling Kit (SP6/T7), Roche, Germany).

Genomic DNAs were isolated by the CTAB-based method (Tel-Zur et al. 1999) with a minor change. Approximately $20 \mu \mathrm{g}$ genome DNA was digested with restriction enzymes (XhoI, SacI or EcoRI), which did not have restriction sites in the probe used. Hybridization was performed at $50^{\circ} \mathrm{C}$ for $16 \mathrm{~h}$ after addition of the DIG-labeled probe into the new DIG Easy Hyb Granules solution (Roche, Germany), which was the same solution as that used for prehybridization. Detections were carried out as indicated by the manufacturer's protocol.

\section{Northern blot analysis}

Total RNAs were isolated by phenol-chloroform extraction (Liu et al. 1994) with a minor change. Hybridization was performed at $68^{\circ} \mathrm{C}$ with $5 \mu \mathrm{g}$ of total RNA as a template and the RNA probe described in Southern blot analysis, according to the manufacturer's protocol. Ethidium bromidestained RNA is shown as a loading control.

\section{Result}

\section{Nitrate uptake}

When nitrate was applied at a concentrations of 10-400 $\mu \mathrm{M} \mathrm{KNO}_{3}$, nitrate uptake by small reed plants rose with the increase in initial nitrate concentration. Net nitrate uptake of W-6 was higher than that of W-8 in the range of nitrate concentrations applied in this experiment (Fig. 1). At the lowest concentration, the difference between $\mathrm{W}-6$ and $\mathrm{W}-8$ was about 3-fold. The difference in nitrate uptake seemed to become greater with the increase in nitrate concentration and, in particular, the highest difference was found at the concentration of $200 \mu \mathrm{M}$. The difference between the clones was due to the response to nitrate concentration; that is, nitrate uptake was saturated at an initial concentration of $50 \mu \mathrm{M}$ in $\mathrm{W}-8$, while the uptake was saturated at an initial concentration of $200 \mu \mathrm{M}$ in W-6. The relationship between initial nitrate concentration and nitrate uptake ratio could be ana-

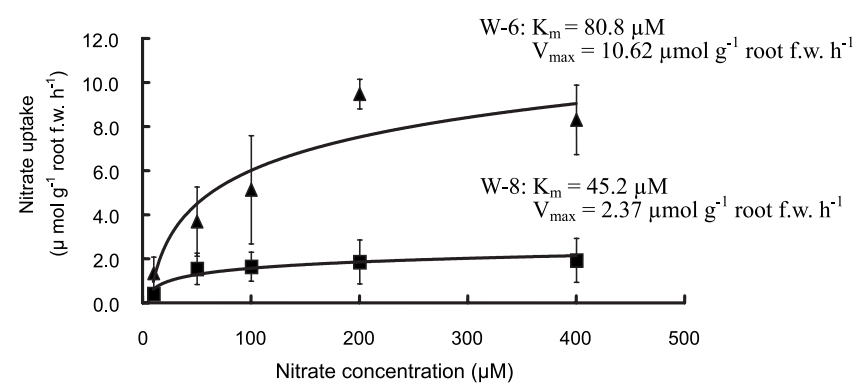

Fig. 1. Difference in nitrate uptake by roots between W-6 (triangle) and W-8 (square). lyzed with Michaelis-Menten kinetics. There were also critical differences in kinetic parameters for nitrate uptake between the two clones (Fig. 1). $\mathrm{K}_{\mathrm{m}} \mathrm{s}$ were 80.8 and $45.2 \mu \mathrm{M}$ and $\mathrm{V}_{\max } \mathrm{s}$ were 10.62 and $2.37 \mu \mathrm{mol} \mathrm{g} \mathrm{g}^{-1}$ root f.w. $\mathrm{h}^{-1}$ in $\mathrm{W}-6$ and $\mathrm{W}-8$, respectively. No significant differences in morphological characters were found between W-6 and W-8.

\section{Isolation of the reed NRT2}

In this experiment, an 1858 bp cDNA fragment was isolated by PCR and RACE methods and was sequenced. In the isolated cDNA fragment, a start codon was found at 108 bp and a stop codon at $1676 \mathrm{bp}$, indicating that the length of the open reading frame (ORF) was $1569 \mathrm{bp}$. The cDNA had 88\% similarity to Zea mays NRT2 (ZmNRT2: GenBank accession no. AY129953) and $87 \%$ similarity to OsNRT2. The deduced amino acid sequence from the isolated cDNA had 523 amino acid residues and had 12 spanning regions across the plasma membrane as predicted with TMpred (Hofmann and Stoffel 1993), which was applied with a minimum of 20 and maximum of 32. At an amino acid sequence level, the deduced sequence had $81 \%$ similarity to ZmNRT2 and $80 \%$ similarity to OsNRT2. The reed NRT2 also had a specific nitrate/nitrite transporter 'signature motif', A-G-W/L-G-N-M$\mathrm{G}$ (Trueman et al. 1996) (Fig. 2), which is located between amino acids residues 189 and 195. The phylogenic relation of NRT2 in higher plants determined using a ClustalW program available at DDBJ (http://hypernig.nig.ac.jp) and Tree view (Page 1996) is shown in Fig. 3, in which the reed NRT2 is shown to be included in a monocot group consisting of rice and maize but is different from the group of the tribe Triticeae. There were three substitutions at amino acid residues 202, 380 and 464 from a comparison with amino acid sequences of the reed NRT2 between W-6 and W-8 (Fig. 2).

Southern blot analysis was performed using genomic DNAs of two reed clones, which were digested with XhoI, $S a c$ I or EcoRI, and the reed NRT2-specific probe. The probe hybridized strongly to five major bands and weakly to four other bands, suggesting that both clones had more than five copies of the reed NRT2. There were no differences in the copy number between W-6 and W-8.

\section{Expression of the reed NRT2}

Northern blot analysis showed that the expression of the reed NRT2 gene was induced 3 hours after nitrate treatment and was strongly expressed in the root (Fig. 4) as demonstrated in other NRT2 (Forde 2000). However, expression of NRT2 was not detected in leaves (Fig. 4). There were differences in NRT2 transcript abundance and expression between W-6 and W-8 (Fig. 4). In W-8, the expression was highest after 3 to 6 hours since nitrate was added and slightly declined until $16 \mathrm{~h}$ after nitrate addition, while in W-6, NRT2 expression was highest $11 \mathrm{~h}$ after nitrate treatment.

\section{Discussion}

In this experiment, the two kinetic parameters, $\mathrm{K}_{\mathrm{m}}$ and 


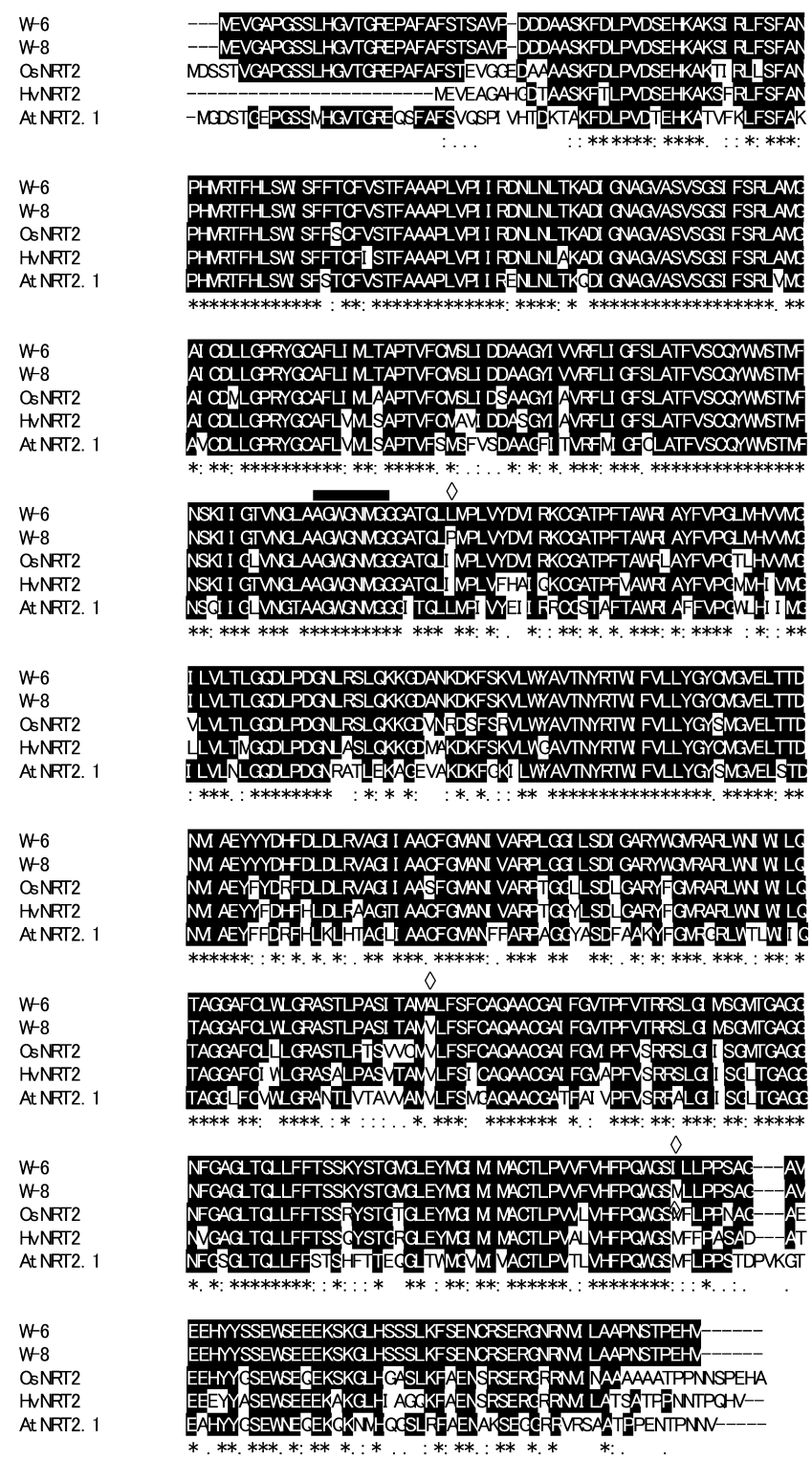

Fig. 2. Comparison of NRT2 amino acid sequences among reed (W-6 and W-8), monocotyledons (OsNRT2 and Hordeum vulgare NRT2 (HvNRT2)) and Arabidopsis thaliana NRT2 (AtNRT2). GenBank protein ID numbers are OsNRT2, BAA33382; HvNRT2, AAC49531; AtNRT2.1, AAC64170. Solid bar shows the specific nitrate/nitrite transporter 'signature motif'. " $\diamond$ " indicates amino acid substitution between W-6 and W-8.

$\mathrm{V}_{\max }$, for HATS for nitrate uptake of two reed clones were 80.8 and $45.2 \mu \mathrm{mol} \mathrm{l}^{-1}$ for $\mathrm{K}_{\mathrm{m}}$ and 10.62 and $2.37 \mu \mathrm{mol} \mathrm{g}^{-1}$ root f.w. $\mathrm{h}^{-1}$ for $\mathrm{V}_{\max }$ in $\mathrm{W}-6$ and $\mathrm{W}-8$, respectively. These values were roughly coincident with those obtained in other higher plants (Rao and Rains 1976, Doddema and Telkamp 1979, Goyal and Huffaker 1986, Barro et al. 1994, Hasegawa and Ichii 1994). Intraspecific differences in nitrate uptake ability have been demonstrated in some plant species such as O. sativa, Lolium perenne and Trifolium repens (Hasegawa and Ichii 1994, Hogh-Jensen et al. 1997). A very interesting result was the clear differences in nitrate uptake kinetic pa-

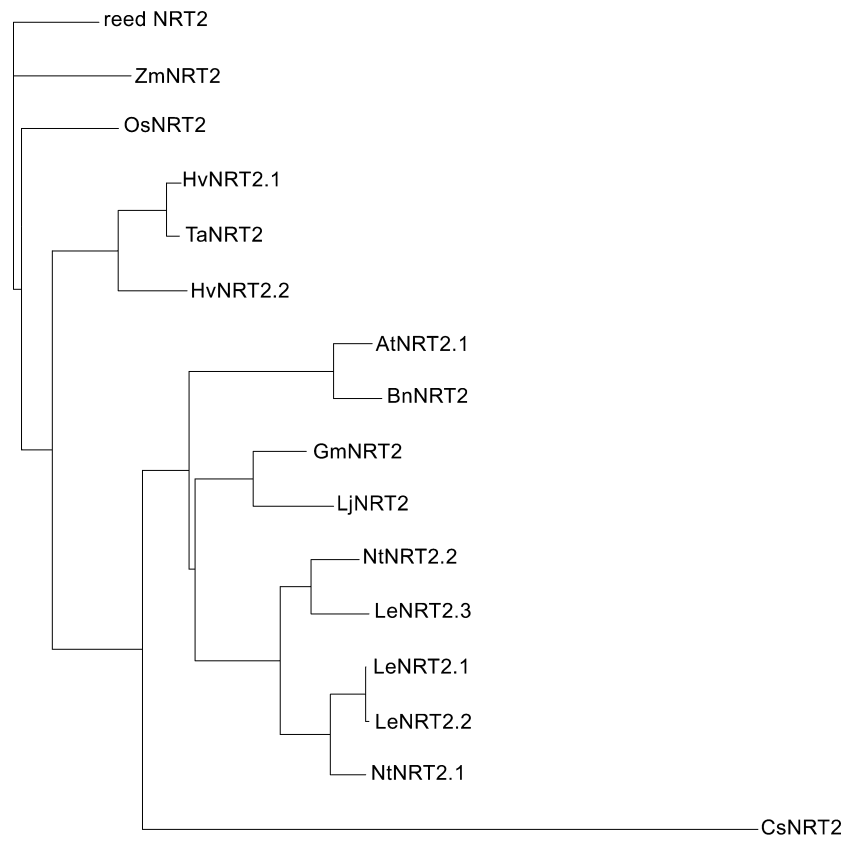

0.1

Fig. 3. Phylogenetic analysis of NRT2 proteins. Amino acid sequences of NRT2 were aligned with ClustalW. GenBank protein ID numbers are Phragmites australis reed NRT2, BAC76606; Zea mays ZmNRT2, AAN05088; Oryza sativa OsNRT2, BAA33382; Hordeum vulgare HvNRT2.1, AAC49531; HvNRT2, AAC49532; Triticum aestivum TaNRT2.1, AAK19519; Arabidopsis thaliana AtNRT2.1, CAB09794; Brassica napus BnNRT2, CAC05338; Glycine max GmNRT2, AAC09320; Lotus japonicus LjNRT2, CAC35729; Nicotiana tabacum NtNRT2.1, CAD89798; NtNRT2.2, CAD89799; Lycopersicon esculentum LeNRT2.1, AAF00053; LeNRT2.2, AAF00054 LeNRT2.3, AAK72402; Chlorella sorokiniana CsNRT2, AAK02066.
W-6

(h) $\quad \begin{array}{llllllllllllllllll}0 & 0.5 & 1 & 1.5 & 2 & 3 & 6 & 11 & 16 & 0 & 0.5 & 1 & 1.5 & 2 & 3 & 6 & 11 & 16\end{array}$

Root NRT

Leaf $\underline{N R T 2}$ (1)

Root RNA

Leaf_RNA

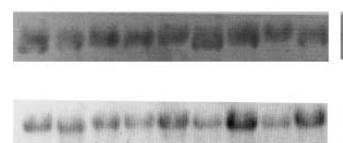

Fig. 4. Northern analysis of the reed NRT2 expression in roots and leaves. Total RNA $(5 \mu \mathrm{g})$ was extracted from roots, which were cultured with $400 \mu \mathrm{M}$ nitrate. Each number means time (h) after nitrate treatment. Loading controls stained with ethidium are shown separately for roots and leaves.

rameters between the two clones; about a 2-fold difference in $\mathrm{K}_{\mathrm{m}}$ and more than a 4-fold difference in $\mathrm{V}_{\max }$. As both clones were progenies of the reed plant collected in the same community, the differences in nitrate kinetic parameters 
indicated the presence of genetic variability in the reed community. This suggests that useful genotypes for efficient removal of nitrate from river and lake water can be found in the reed community, because diverse chromosome numbers have been reported in the reed community (Ishii and Kadono 2002) and isozyme polymorphism has also been reported in reeds distributed in the Lake Biwa region (Nomiyama et al. unpublished). From these results, it should be possible to breed a unique reed with increased nitrate uptake ability. Further screening and selection for nitrate uptake in reeds are necessary.

As the first step in the molecular analysis for differences in nitrate uptake ability in the two clones, we attempted to isolate the reed NRT2. A putative reed NRT2 cDNA fragment (1858 bp) was isolated using PCR and RACE methods and its deduced amino acid sequence of putative NRT2 had a high similarity to NRT2 identified in other higher plants, notably being very similar to that in the monocot group (Fig. 3). Furthermore, there was a 'signature motif' only for the nitrate/nitrite transporter family in the major facilitator superfamily (Fig. 2; Trueman et al. 1996, Amarasinghe et al. 1998). The putative reed NRT2 had 12 spanning regions estimated by the deduced amino acid sequence, and they were the same as those of in other plant NRT2 (Forde 2000). Northern blot analysis revealed that the cDNA isolated in this experiment was transcribed specifically in the roots treated with nitrate. These results indicated that the isolated cDNA is NRT2 of reed. (GenBank accession no. AB096061.)

In higher plants, NRT2 comprises several families (Orsel et al. 2002b). In reed, Southern blot analysis demonstrated more than five bands thought to be NRT2 in both reed clones, indicating that there are also several families of reed NRT2. However, to determine the number of copies, the polyploidy level must be taken into account, because diversity in polyploidy among the reed populations around Lake Biwa has been reported (Ishii and Kadono 2001). As the polyploidy level of the two clones was still unclear, further analysis of the banding pattern of Southern blot in relation to polyploidy is necessary. Three amino acid substitutions were found between W-6 and W-8. At present, it is not clear whether the difference in nitrate uptake ability is due to the amino acid substitutions or not.

The reed NRT2 was induced by nitrate and the transcription started within 3 hours after nitrate treatment (Fig. 4). The expression pattern of reed NRT2 revealed a difference between the two clones: in $\mathrm{W}-8$ the reed NRT2 maintained a high expression level from the start of transcription, while the amount of NRT2 mRNA in W-6 was gradually increased from the beginning of transcription. It is not clear whether the difference in the nitrate uptake ratio is due to the difference in reed NRT2 expression between W-6 and W-8. Further investigation is necessary on the relationship timedependent NRT2 expression and nitrate uptake.

When reed plants grow under flooded conditions, ammonium is thought to be a major source of nitrogen as rice.
Under such conditions, the expression of $N R T 2$ is repressed (Orsel et al. 2002a). However, reed roots from the nodes can develop into the water, where the most available nitrogen form is nitrate. Improvement of ability of nitrate uptake from roots that have developed from the nodes into water is an excellent strategy for removing nitrate. Furthermore, the present results imply the possibility of selecting reed genotypes with high removing other eutrophic substances and pollutants.

\section{Acknowledgements}

We thank Dr. Irie of the University of Shiga Prefecture for critical reading the manuscript. This research was financially supported by a Sasakawa Scientific Research Grant from the Japan Science Society to R. A. (research number, 14-256).

\section{Literature Cited}

Amarasinghe,B.H.R.R., G.L.de Bruxeloles, M.Braddon, I.Onyeocha, B.G.Forde and M.K.Udvardi (1998) Regulation of GmNRT2 expression and nitrate transport activity in roots of soybean (Glycine max). Planta 206: 44-52.

Asaeda,T., J.Manatunge, T.Fujino and D. Sovira (2003) Effects of salinity and cutting on the development of Phragmites australis. Wetlands Ecol. Mgmt. 11: 127-140.

Barro,F., A.G.Fontes and J.M.Maldonato (1994) Nitrate uptake and reduction by durum wheat (Triticum turgidum) and tritoreum (Hordeum chilense $\times$ Triticum turgidum). J. Plant Physiol. 143: 313-317.

Doddema,H. and G.P.Telkamp (1979) Uptake of nitrate by mutants of Arabidopsis thaliana, disturbed in uptake or reduction of nitrate. 2. Kinetics. Plant Physiol. 45: 332-338.

Forde,B.G. (2000) Nitrate transporters in plants: structure, function and regulation. Biochim. Biophys. Acta 1465: 219-235.

Goyal,S.S. and R.C.Huffaker (1986) The uptake of $\mathrm{NO}_{3}{ }^{-}, \mathrm{NO}_{2}{ }^{-}$, and $\mathrm{NH}_{4}{ }^{+}$by intact wheat (Triticum aestivum) seedlings. 1. Induction and kinetics of transport systems. Plant Physiol. 82: 10511056.

Hasegawa,H. and M.Ichii (1994) Variation in Michaelis-Menten kinetic parameters for nitrate uptake by the young seedlings in rice (Oryza sativa L.). Breed. Sci. 44: 383-386.

Hofmann, K. and W.Stoffel (1993) A database of membrane spanning proteins segments. Biol. Chem. Hoppe-Seyler 374: 166.

Hogh-Jensen,H., B.Wollenweber and J.K.Schjoerring (1997) Kinetics of nitrate and ammonium absorption and accompanying $\mathrm{H}^{+}$ fluxes in roots of Lolium perenne $\mathrm{L}$. and $\mathrm{N}_{2}$-fixing Trifolium repens L. Plant Cell Environ. 20: 1184-1192.

Ishii,J. and Y.Kadono (2001) Classification of two Phragmites species, $P$. australis and $P$. japonica, in the Lake Biwa-Yodo river system, Japan. Acta Phytotax. Geobot. 51: 187-201.

Ishii,J. and Y.Kadono (2002) Factors influencing seed production of Phragmites australis. Aquat. Bot. 72: 129-141.

Koppitz,H. (1999) Analysis of genetic diversity among selected populations of Phragmites australis world-wide. Aquat. Bot. 64: 209-221.

Krapp,A., V.Fraisier, W.-R.Scheible, A.Quesada, A.Gojon, M.Stitt, M.Caboche and F.Daniel-Vedele (1998) Expression studies of 
$N r t 2: 1 N p$, a putative high-affinity nitrate transporter: evidence for its role in nitrate uptake. Plant J. 14: 723-731.

Lake Biwa Research Institute (2002) Effects on lake water quality and control measures of non-point pollution loadings at Lake Biwa. LBRI Project Research Report, No.01-A01 (Vol.2) p.9-87 (in Japanese).

Liu,Z., D.B.Batt and G.G.Carmichael (1994) An improved rapid method of isolating RNA from cultured cells by SDS-acid phenol/chloroform extraction. BioTechniques 16: 56-57.

Orsel,M., S.Filleur, V.Fraisier and F.Daniel-Vedele (2002a) Nitrate transport in plants: which gene and which control? J. Exp. Bot. 53: 825-833.

Orsel,M., A.Krapp and F.Daniel-Vedele (2002b) Analysis of the NRT2 nitrate transporter family in Arabidopsis. Structure and gene expression. Plant Physiol. 129: 886-896.

Page, R.D.M. (1996) TREEVIEW: An application to display phylogenetic trees on personal computers. Computer Appl. Biosci. 12: 357-358.

Quesada,A., A.Krapp, L.J.Trueman, F.Daniel-Vedele, E.Fernandez, B.G.Forde and M.Caboche (1997) PCR-identification of a
Nicotiana plumbaginifolia cDNA homologous to the highaffinity nitrate transporters of the $\mathrm{crnA}$ family. Plant Mol. Biol. 34: $265-274$.

Rao,K.P. and D.W.Rains (1976) Nitrate absorption by barley. 1. Kinetics and energetics. Plant Physiol. 57: 125-132.

Tel-Zur,N., S.Abbo, D.Myslabodski and Y.Mizrahi (1999) Modified CTAB procedure for DNA isolation from epiphytic cacti of the genera Hylocereus and Selenicereus (Cactaseae). Plant Mol. Biol. Reptr. 17: 249-254.

Trueman,L.J., A.Richardson and B.G.Forde (1996) Molecular cloning of higher plant homologues of the high-affinity nitrate transporters of Chlamydomonas reinhardtii and Aspergillus nidulans. Gene 175: 223-231.

Tsay, Y.-F., J.I.Schroeder, K.A.Feldmann and N.M.Crawford (1993) The herbicide sensitivity gene $\mathrm{CHL} 1$ of Arabidopsis encodes a nitrate-inducible nitrate transporter. Cell 72: 705-713.

Wang, R. and N.M.Crawford (1996) Genetic identification of a gene involved in constitutive, high-affinity nitrate transport in higher plants. Proc. Natl. Acad. Sci. USA 93: 9297-9301. 